\title{
Perianal fistülün tanısında, sınıflandırılmasında ve değerlendirilmesinde Manyetik Rezonans Görüntüleme'nin önemi
}

\section{Importance of Magnetic Resonance Imaging in diagnosis, classification and evaluation of perianal fistula}

\author{
Mesut Sivri ${ }^{1}$, Mustafa Koplay ${ }^{2}$, Alaaddin Nayman ${ }^{2}$, Hakan Cebeci ${ }^{2}$, İbrahim Güler ${ }^{2}$, \\ Emine Uysal $^{2}$, Yahya Paksoy ${ }^{2}$
}

Öz

Amaç: Manyetik rezonans görüntüleme (MRG) perianal bölgenin değerlendirilmesinde yüksek güvenilirliğe sahip non-invaziv bir yöntemdir. Bu çalışmada, perianal fistül tanısı alan hastaların preoperatif MRG bulguları ve özellikle sınıflandırmanın görüntülerle birlikte sunulması amaçlandı. Yöntemler: Perianal fistül tanısı alan 57 hastanın demografik özellikleri ve kontrastlı konvansiyonel ve difüzyon MRG bulguları retrospektif olarak değerlendirildi. Perianal fistül sınıflandırılması MRG bulgularını temel alan 'St James Üniversite Hastanesi (SJUH) Sinıflaması' referans alınarak yapıldı. Bulgular: Çalışmaya 57 hasta (44 erkek ve 13 kadın: yaş aralığı 18-72 yıl; ortalama yaş 45,7 yıl) dahil edildi. Hastaların büyük çoğunluğunun esas yakınması makatta ağrı ve akıntı idi. Bazı hastalar ek olarak makatta kaşıntı, şişlik ve kızarıklık semptomları da bildirdi. 37 hastada tip 1, dokuz hastada tip 2, dört hastada tip 3, beş hastada tip 4, iki hastada ise tip 5 fistül saptandı. Anal kanala açılım yerleri 21 hastada saat 6, 10 hastada saat 7 olarak saptandı. Konvansiyonel ve difüzyon MRG ile fistül traktı, apse varlığı, rektuma açılım yeri, sfinkterle veya komşu anatomik yapılarla ilişkisi tüm hastalarda net olarak değerlendirildi.

Sonuç: Anal kanal ve perine derisi arasında meydana gelen anormal bağlantı perianal fistül olarak adlandırılmaktadır. Genellikle tekrarlayan anorektal apselerin komplikasyonudur. Crohn, tüberküloz, malignite gibi inflamatuar süreçlere sekonder de gelişebilir. Tedavide esas yöntem cerrahidir. Cerrahi yetersizliğine bağlı rekürrens oldukça sıktır. MRG bulgularının iyi bilinmesi ve cerrahın iyi yönlendirilmesi ile rekürrens oranı en aza indirgenebilmektedir.

Anahtar Kelimeler: Manyetik rezonans görüntüleme, Perianal fistül

\section{Abstract}

Aim: Magnetic resonance imaging (MRI) is a non-invasive and high reliability procedure for evaluation of perianal area. In this study, our purpose is to present preoperative MRI findings and classification with images in diagnosed perianal fistula patients.

Methods: Contrast enhanced (CE) conventional MRI images, diffusion weighted MRI images and demographics of 57 patients were retrospectively evaluated. Perianal fistula classification is based on $\mathrm{St}$ James University Hospital (SJUH) classification system.

Results: 57 patients ( 44 men and 13 women, average of 18 to 72 years, average age of 45.7 year) were included in this study. Most of the patients had symptoms of rectal pain and discharge. Some patients had additional complaints like rectal itching, swelling and erythema. 37 patients had grade 1 , nine patients had grade 2 , four patients had grade 3 , five patients had grade 4 and two patients had grade 5 fistula. Fistula opening positions into anal canal were 6 o'clock in 21 patients, 7 o'clock in 10 patients. Fistula tract, its opening position into anal canal, presence of abscess and its relationship with sphincters or neighboring anatomical structures were clearly appreciated with conventional and diffusion weighted MRI in all patients.

Conclusion: Perianal fistula is the abnormal connection between anal canal and perinea. It is usually a complication of anorectal abscess. It could occur secondary to inflammatory processes like Crohn's disease, tuberculosis or malignancy. Surgery is considered as the primary treatment. Recurrence due to surgical inadequacy is common. Recurrence rates could be minimized with a good knowledge of MRI findings and well informing the surgeon.

Keywords: Magnetic resonance imaging, Perianal fistula
1 Sağlık Bilimleri Üniversitesi, Konya Eğitim ve Araștırma Hastanesi, Radyoloji Anabilim Dalı, Konya, Türkiye

2 Selçuk Üniversitesi, Radyoloji Anabilim Dalı, Konya, Türkiye

Etik Kurul: Çalışmanın retrospektif dizaynından dolayı etik kurul onayı alınmamıştır.

Ethical approval: Due to retrospective design of the study, no ethical approval has been taken.

Çıkar Çatışması: Yazarlar çıkar çatışması bildirmemişlerdir. Conflict of Interest: No conflict of interest was declared by the authors.

Finansal Destek: Yazarlar bu olgu için finansal destek almadıklarını beyan etmişlerdir.

Financial Disclosure: The authors declared that this case has received no financial support.

Geliş Tarihi / Received

21.03 .2017

Kabul Tarihi / Accepted 02.04.2017

Yayın Tarihi / Published 16.04.2017

Sorumlu yazar / Corresponding author

Mustafa Koplay

Adres: Selçuk Üniversitesi, Tıp Fakültesi, Radyoloji Anabilim Dalı, Konya, Türkiye.

Tel: +90332 6060505

E-posta: koplaymustafa@hotmail.com

C Copyright 2017 ACEM 


\section{Giriş}

Anal kanal ve perine derisi arasında meydana gelen anormal bağlantı perianal fistül olarak adlandırılmaktadır [1]. Nadir görülür ancak ciddi bir morbidite nedenidir. Prevelansı ortalama \%0,01 olarak bilinmektedir ve erkeklerde kadınlara göre 2 kat daha sık görülmektedir [1,2]. Genellikle tekrarlayan anorektal apselerin komplikasyonudur [2-4]. Crohn, tüberküloz, malignite gibi inflamatuar süreçlere sekonder de gelişebilir. Ağrı yakınması sık olmasına rağmen en sik bulgu akıntı olarak bilinmektedir (\%65) [5]. Tedavi genellikle cerrahidir ancak cerrahi yetersizliğe bağlı rekürrens oranı oldukça yüksektir. Rekürrens oranları \%25'lere ulaşmaktadır [3,5]. Başarılı cerrahi tedavi için iyi bir preoperatif değerlendirme gerekmektedir. Primer fistül traktının yerleşim yerinin, sekonder uzanımlarının, apse varlığının ve fistülün pelvik yapılarla ilişkisinin bilinmesi cerrahi başarısını ve rekürrens oranlarını etkileyen önemli faktörlerdendir [1,2,4]. Manyetik rezonans görüntüleme (MRG) perianal fistül tanısında ve preoperatif değerlendirilmesinde artan sıklıkla tercih edilen, oldukça etkin, non-invaziv bir tanı yöntemidir [4]. MRG ile fistülün yaygınlığı ve uzanımları, apse varlığı, pelvik diyafram ve iskiorektal fossa ile ilişkisi, sfinkter komşulukları açık bir şekilde ortaya konulabilmektedir. Bunun sonucunda cerrahın tedavi başarısı giderek artmakta, rekürrens ve fekal inkontinans gibi komplikasyon oranları giderek azalmaktadır [1,4,6-8].

$\mathrm{Bu}$ çalışmada, perianal fistül tanısı alan hastaların preoperatif MRG bulguları ve özellikle sınıflandırmanın görüntülerle birlikte sunulması amaçlandı.

\section{Gereç ve Yöntemler}

01.06.2012-01.12.2015 tarihleri arasında perianal fistül tanısı alan 57 hastanın kontrastlı konvansiyonel ve difüzyon MRG görüntüleri retrospektif olarak değerlendirilmiştir. Hastaların demografik bilgilerine ve başvuru şikayetlerine hastane bilgi yönetim sisteminden (HBYS) ulaşılmıştır. Çekimler Siemens Aera1.5 T MRG (Siemens, Germany) ile 8 kanallı faz dizilimli vücut bobini kullanılarak yapılmıştır. Aksiyel kesitler anal kanala dik, koronal ve sagital kesitler anal kanala paralel olacak şekilde aksiyel T1A ve T2A, aksiyel yağ baskılı T1A ve T2A, koronal yağ baskılı T2A, sagittal T2A, intravenöz gadolinyum $(0,1 \mathrm{mmol} / \mathrm{kg})$ sonrası yağ bask1lı T1A ve difüzyon ağırlıklı görüntüler perianal fistül protokolü ile rutin olarak alınmıştır. Fistül lokalizasyonu saat kadranında (anal saat) aksiyel görüntülere göre belirlenmiştir (Şekil 1). Fistül sınıflandırılması anatomik görüntüleme bulgularını temel alan 'St James Üniversite Hastanesi (SJUH) Sinıflaması' referans alınarak yapılmıştır [1]. Evre 1 basit lineer inter sfinkterik fistül, evre 2 apse veya sekonder uzanımı bulunan intersfinkterik fistül, evre 3 transsfinkterik fistül, evre 4 iskiorektal veya iskioanal fossada apse veya sekonder uzanımı bulunan transsfinkterik fistül ve evre 5 supralevator-translevator fistül olarak kabul edildi.

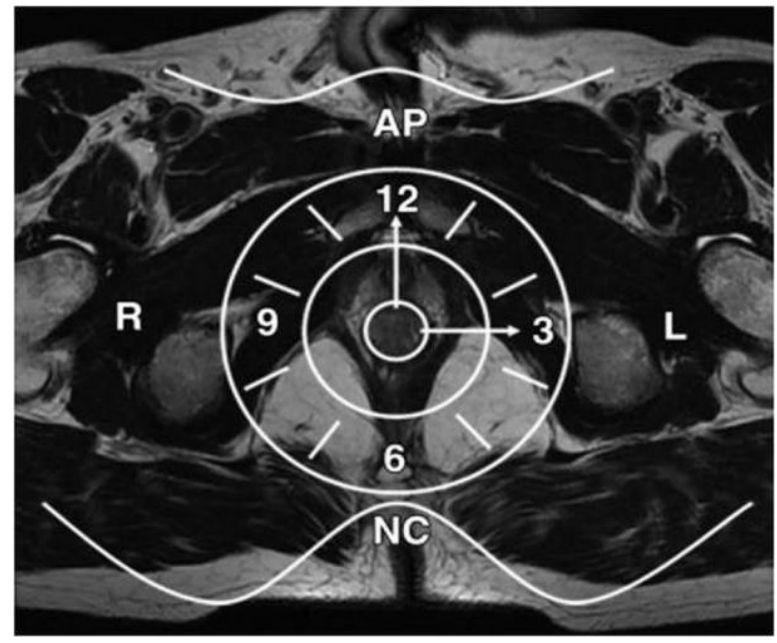

Şekil 1: Anal Saat

\section{Bulgular}

Çalışmaya alınan 57 hastanın yaş aralığı 18-72 yıl ve yaş ortalaması 45,7 yıl olarak bulundu. Hastaların 44'ü erkek, 13'ü kadındı. \%72 hastada makatta ağrı, \%63 hastada ise akıntı büyük çoğunluğunun esas yakınması olarak dikkat çekmekteydi. Makatta kaşıntı, kabızlık ve kızarıklık diğer nadir görülen semptomlardı (Tablo 1). 57 hastanın 46'sında intersfinkterik (\%81), 9'unda transsfinkterik (\%16), 2'sinde ise supralevator (\%3) fistül traktı saptand. İntersfinkterik fistül olan hastaların 9'unda, transsfinkterik fistül bulunan hastaların 5'inde apse eşlik etmekteydi. 37 hastada tip 1 (Resim 1), 9 hastada tip 2 (Resim 2), 4 hastada tip 3 (Resim 3), 5 hastada tip 4 (Resim 4), 2 hastada ise tip 5 (Resim 5) fistül saptandı (Tablo 2). Anal kanala açılım yerleri 21 hastada saat 6,10 hastada saat 7, alt1 hastada saat 5 , beş hastada saat 1 , dört hastada saat 12 , dört hastada saat 11 , dört hastada saat 3 , bir hastada saat 10 , bir hastada saat 8 ve bir hastada saat 2 olarak saptandı (Tablo 3). Birinci sıklıkla saat 6, ikinci sıklıkla saat 7 en sık anal kanala açılım yerleriydi. Konvansiyonel ve difüzyon MRG ile fistül sinıflandırılması ve değerlendirilmesi kolaylıkla yapılabildi. Sinıflamada temel alınan fistül traktı, apse varlığı, anal kanala açılım yeri, sfinkterle veya komşu anatomik yapılarla ilişkisi tüm hastalarda net olarak değerlendirildi.

Tablo 1: Başvuru semptomları

\begin{tabular}{ll} 
Klinik & Sayı \\
\hline Ağrı & 41 \\
Akıntı & 36 \\
Kaşıntı & 6 \\
Şişlik & 5 \\
Kızarıklık & 9 \\
Kabızlık & 3 \\
Diğer & 7
\end{tabular}

Tablo 2: St James's University Hospital sinıflamasına göre evre oranları

\begin{tabular}{lll} 
Evre & Say1 & Oran $(\%)$ \\
\hline 1 & 37 & 65 \\
2 & 9 & 16 \\
3 & 4 & 7 \\
4 & 5 & 9 \\
5 & 2 & 3
\end{tabular}




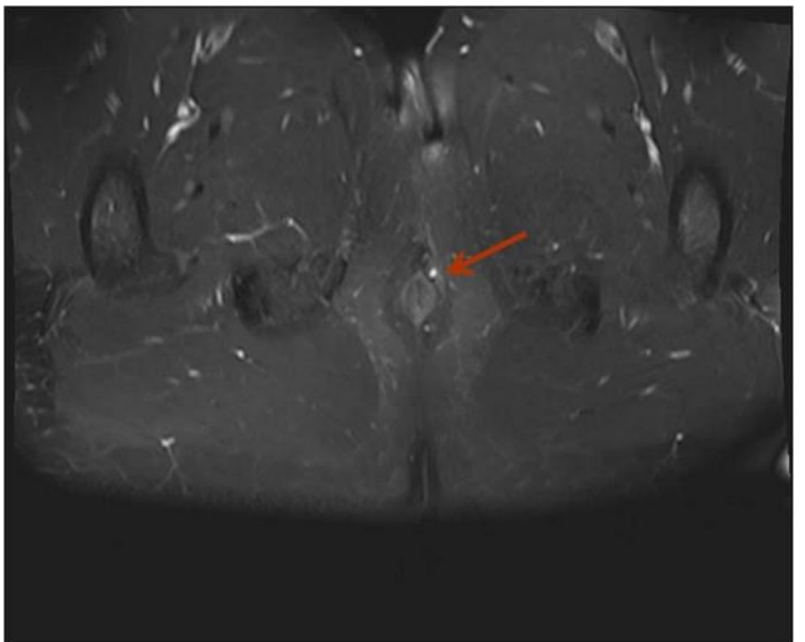

Resim 1: Aksiyel yağ baskılı T2 ağırlık görüntüde evre 1 basit lineer intersfinkterik fistül.

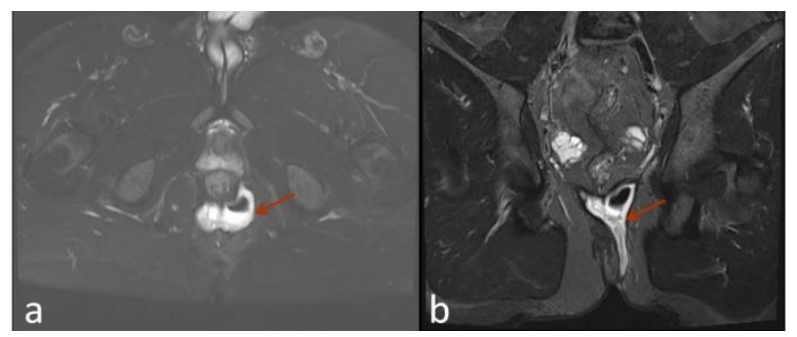

Resim 2: Aksiyel (a) ve koronal (b) yağ baskı1ı T2 ağırlıklı görüntülerde at nalı şeklinde apsenin eşlik ettiği evre 2 intersfinkter fistül görülmektedir (ok).

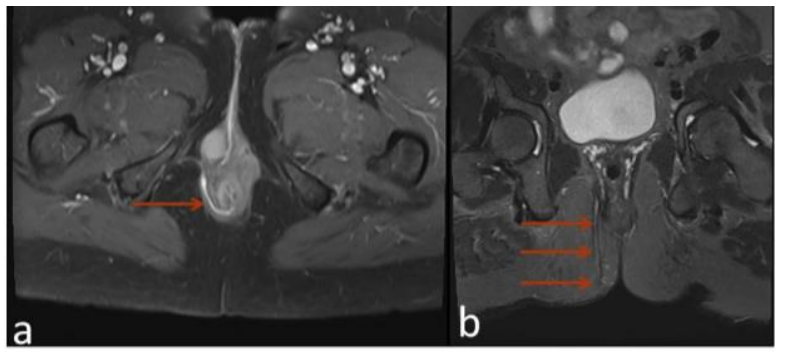

Resim 3: Aksiyel (a) ve koronal (b) yağ baskılı T2 ağırlıklı görüntülerde evre 3 transsfinkterik fistül görülmektedir (ok).

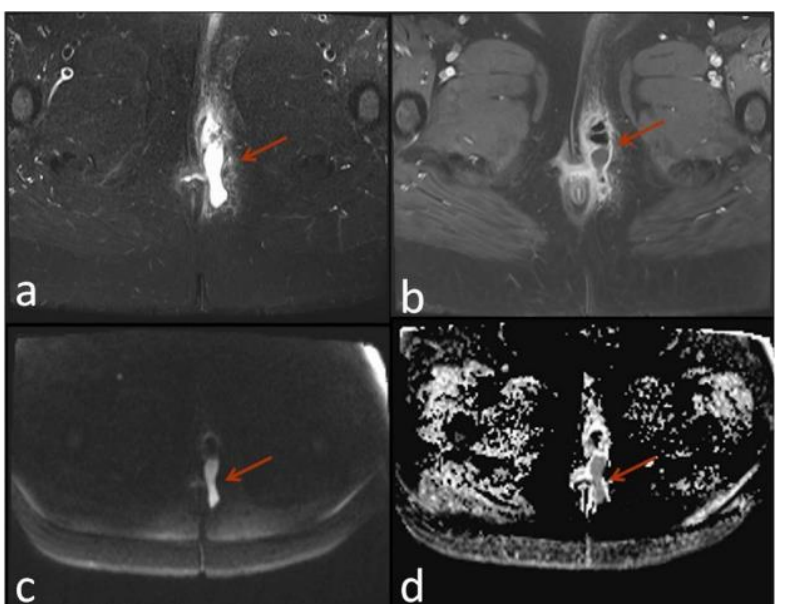

Resim 4: Aksiyel yağ bask1lı T2 (a) ve kontrastlı yağ bask1lı T1 ağırlıklı görüntülerde evre 4 iskiorektal/iskioanal fossada apsenin eşlik ettiği transsfinkterik fistül görülmektedir (ok). Difüzyon ağırlık görüntüde (c) ve ADC haritasında (d) difüzyon kısitlanması mevcuttur (ok).

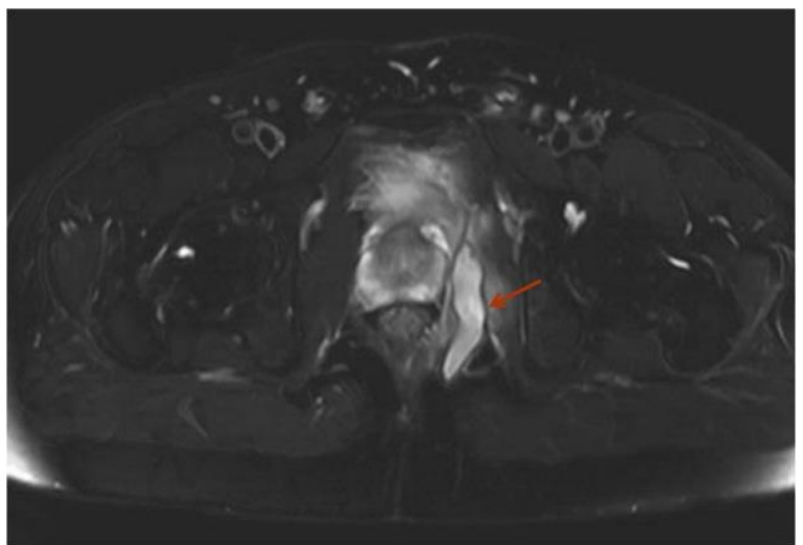

Resim 5: Aksiyel yağ baskılı T2 ağırlıklı görüntüde evre 5supralevatör fistül görülmektedir (ok)

Tablo 3.:Anal saate göre internal fistül traktının açılım yerleri

\begin{tabular}{ll} 
Anal saat & Say 1 \\
\hline Saat 1 & 5 \\
Saat 2 & 1 \\
Saat 3 & 4 \\
Saat 4 & 0 \\
Saat 5 & 5 \\
Saat 6 & 21 \\
Saat 7 & 10 \\
Saat 8 & 1 \\
Saat 9 & 0 \\
Saat 10 & 1 \\
Saat 11 & 4 \\
Saat 12 & 4
\end{tabular}

\section{Tartışma}

Perianal fistül Hipokrat zamanından beri bilinen ve yüzyıllar önce tanımlanmış ciddi bir morbidite nedenidir [1]. Goodsall 1900 yılında deri ve anüs arasındaki fistül traktını tanımlamıştır [9]. 1976 yılında ise Park ve arkadaşları, cerrahi uygulamada yaygın olarak kullanılan anal anatomi ile ilişkili fistül sınıflandırmasını tanımlamışlardır [2].

Perianal fistül en s1k idiopatik olarak görülmektedir. İdiopatik fistül etyolojisi hakkında bilinen en yaygın teori kriptoglandüler hipotezdir [10]. İntramuskuler anal gland enfeksiyonunun kronik fazını temsil etmektedir. Öncelikle intersfinkterik gland enfeksiyonu oluşur. Enfeksiyonu drene eden duktusun tıkanması sonucunda ise intersfinkterik fistül traktı veya apse oluşmaktadır. $\mathrm{Bu}$ alanda oluşan kronik enfeksiyon persistan fistül traktının ve tekrarlayan apselerin başlıca nedenidir. Crohn hastalığı, pelvik enfeksiyon, tüberküloz, divertikülit, doğum travması, pelvik malignensi ve radyoterapi gibi durumlara sekonder de gelişebilmektedir [4,10].

Tedavide genellikle cerrahi tercih edilmektedir ve cerrahi tedavinin türünü primer fistül traktının seyri, eşlik eden sekonder fistül traktları veya apse varlığı, rektuma açılım yeri, sfinkterle veya komşu anatomik yapılarla ilişkisi gibi durumlar etkilemektedir. Örneğin, basit intersfinkterik fistüllerde (tip 1) fistülotomi veya fistülektomi gibi basit cerrahi işlemler yeterli olurken, eşlik eden apse varlığında veya komplike fistüllerde bir çok farklı kolorektal cerrahi metodları uygulanmaktadır [11]. Ayrıca cerrahi sırasında fekal inkontinans gibi önemli bir morbid komplikasyonun oluşmaması için eksternal sfinkter bütünlüğünü korumak gerekmektedir $[1,4,12]$. En uygun cerrahi stratejinin belirlenmesinde ve rekürrens-komplikasyon oranlarının azaltılmasında preoperatif görüntülemeyle fistül sınıflandırılması 
yapılması ve komşu anatomik yapıların gösterilmesi oldukça önemlidir $[13,14]$.

Eskiden perianal fistülü belirlemek için birçok görüntüleme yöntemleri kullanılmıştır. Yapılan retrospektif bir çalışmada kontrastlı konvansiyonel fistülografi tekniğiyle fistülün doğru saptanma oranı \%16 gibi oldukça düşük oranlarda bulunmuştur [15]. İki önemli dezavantajı sekonder fistül traktlarını saptayamaması ve fistülün sfinkter ilişkisini gösterememesidir. Preoperatif görüntülemede kullanılan diğer tanı yöntemlerinden kontrastlı bilgisayarlı tomografi (BT), BT fistülografi ve anal endosonografi doğru tanı oranlarını arttırmakla birlikte komşu yapılarla ilişkiyi ve sekonder traktları göstermedeki yetersizliği nedeniyle artık sık olarak kullanılmamaktadır [16-19]. BT'nin yumuşak doku kontrastının düşük olmasından dolayı küçük apse ve fistüller gösterilememektedir [16]. BT fistülografi invaziv ve ağrılı bir yöntemdir. Ayrıca sekonder enfeksiyonlara yol açabilmektedir [17]. Endoluminal problar kullanılarak yapilan anal endosonografi intersfinkterik fistülleri saptamada ve fistülün anal sfinkterle ilişkisini göstermede başarılı bir yöntemdir. Ancak yüzeyel apselerin supra ve ekstrasfinkterik fistüllerin saptanmasında yetersiz kalmaktadır [18].Günümüzde MRG perianal fistüllerin tanısında preoperatif ve postoperatif değerlendirilmesinde en çok tercih edilen non-invaziv bir görüntüleme yöntemi olup yapılan birçok çalışmada oldukça yüksek duyarlılık ve özgüllük değerlerine sahiptir. Fistül traktını saptamada endosonografi ile duyarlılık \%81 saptanmışken, aynı duyarlılık MRG'de \%91 olarak belirtilmektedir. Fistülün internal açılım yerinin gösterilmesi endosonografi ile \%91, MRG ile \%97 olarak bulunmuştur [19].

Özellikle dinamik postkontrast yöntemlerin ve difüzyon ağırlıklı görüntüleme tekniklerinin kullanılmasıyla enfeksiyöz sürecin yaygınlığını, fistülün karakterizasyonunu, komşu anatomik yapılarla (sfinkterler gibi) ilişkisi, fistülün internal ve eksternal açılım yerleri, apseler artan doğruluk oranlarıyla açık bir şekilde gösterilebilmektedir. MRG'nin preoperatif kullanılması ve doğru fistül sınıflandırılmasının belirlenmesiyle önceden oldukça yüksek oranlarda görülen postoperatif rekürrens ve komplikasyon oranlarının azalmasını sağlamıştır $[1,4,6]$.

Perianal fistüllerde, 1976 yılında Park ve arkadaşlarının tanımladı̆̆ 1 Park's sinıflaması, 2000 yılında Morris ve arkadaşlarının tanımladığı "St James's University Hospital" sınıflaması olmak üzere iki temel sınıflandırma sistemi kullanılmaktadır [1,2]. Park ve arkadaşları, fistül traktının koronal plandaki seyrine, internal ve eksternal sfinkterle olan ilişkisine göre perianal fistül sınıflandırılmasını intersfinkterik, transsfinkterik, suprasfinkterik ve ekstrasfinkterik olmak üzere dörde ayırmışlardır. İntersfinkterik fistül $\% 45$, transfinkterik fistül $\% 30$, suprasfinkterik fistüller $\% 20$, ekstrasfinkterik fistüller $\% 5$ oranında görülmektedir [2].

Park's sınıflanması cerrahi bir sınıflandırma olup, MRG bulgularını içermemektedir. $\mathrm{Bu}$ sebeple Morris ve arkadaşları anatomik görüntüleme bulgularını içeren "St James's University Hospital" sınıflamasını tanımlamışlardır. Aksiyal ve koronal planda anatomik noktalar kullanılarak primer traktusla birlikte sekonder uzanımları ve eşlik eden apselerin de tanımlandığı radyolojik bir sınıflamadır. Cerrahi plan için gerekli bilgileri içermesi ve radyolojik olarak kolay anlaşılabilir olması nedeniyle günümüzde tercih edilen sinıflama sistemidir. $\mathrm{Biz}$ de çalışmamızda bu sınıflama sistemini kullandık. Bu sınıflamada fistüller beş evreye ayrılmaktadır. Evre 1 basit lineer intersfinkterik fistüldür. Fistül traktı eksternal sfinkterle sınırlanmıştır. Evre 2'de intersfinkterik fistüle apse veya sekonder traktus eşlik etmektedir. Fistül traktı, apse veya sekonder fistül eksternal sfinkterle sınırlanmıştır. Evre 3 transsfinkterik fistüldür. Fistül eksternal sfinkteri geçerek iskiorektal veya iskioanal fossadan aşağıya uzanır ve cilde açılır. Apse ve sekonder trakt eşlik etmez. Evre 4'de transsfinkterik fistüle iskioanal fossada apse veya sekonder traktuslar eşlik eder. Evre 5 fistülde supralevator ve translevator uzanım vardır. Fistül levator ani kasının üzerine uzanmaktadır [1].

Morris ve arkadaşları intersfinkterik fistülün $\% 75$ oranında, transsfinkterik fistülün ise $\% 20$ oranında görüldüğünü belirtmişlerdir [1]. Bizim sonuçlarımız bu çalışma ile uyumlu bulunmuştur.

2012 yılında Criado ve arkadaşlarının [4] yaptığ 178 hastalık bir çalışmada evre $1 \% 24,7$, evre $2 \% 18,5$, evre $3 \% 24,2$, evre $4 \% 25,3$ ve evre $5 \% 7,3$ çıkmıştır. Evre 3 ve 4 'ün yüksek oranda çıkması, evre 1 'in preoperatif medikal tedaviye iyi yanıt vermesine, evre 3 ve 4'ün ise medikal tedaviye yanıt vermemesine bağlı olabileceği düşünülmüştür. Tüm hastalarda görüntüleme sekanslarıyla patoloji açık bir şekilde ortaya konmuştur [4].

Halligan ve arkadaşlarının [12] yaptığı çalışmada ve önceki çalışmalarda perianal fistülün sıklıkla genç orta yaş erkeklerde görüldüğü belirtilmiştir. Bizim çalışmamızda da erkeklerde daha sık olduğu ve yaş ortalamasının bu çalışmalarla benzer olduğu görülmüştür. Önceki çalışmalarda akıntı en sık semptom olarak dikkat çekerken, bizim çalışmamızda farklı olarak ağrı en sık, akıntı ise ikinci sıklıkla bulunmuştur. Yine bu çalışmada bizim çalışmamızla paralel olarak fistül traktının internal açılım yerinin en sık saat 6 hizası olduğu bildirilmiştir $[1,4,20]$.

Sonuç olarak, fistül traktını tanımlamada, anal sfinkter mekanizmasını, fistüllerin pelvik diyafram ve iskiorektal fossa ile ilişkisini, sekonder fisstül veya apse varlığının saptanmasında MRG yüksek güvenilirliğe sahip non-invaziv bir yöntemdir. Preoperatif görüntülemede rekürrens ve komplikasyon oranının azaltılmasında MRG altın standart olarak dikkat çekmektedir.

\section{Kaynakça}

1. Morris J, Spencer JA, Ambrose NS. MR imaging classification of perianal fistulas and its implications for patient management. Radiographics 2000; 20:623-35.

2. Parks AG, Gordon PH, Hardcastle JD. A classifica $\neg$ tion of fistula-inano. Br J Surg 1976; 63: 1-12.

3. Seow-Choen, Phillips RK. Insights gained from the management of problematical anal fistulae at St. Mark's Hospital, 1984-88. Br J Surg 1991; 78: 539-41.

4. de Miguel Criado J, del Salto LG, Rivas PF, et al. MR imaging evaluation of perianal fistulas: spectrum of imaging features. Radiographics 2012; 32:175-94.

5. Sainio P. Fistula-in-ano in a defined population. Incidence and epidemiological aspects. Ann Chir Gynaecol 1984; 73: 219-24.

6. Beckingham IJ, Spencer JA, Ward J, Dyke GW, Adams C, Ambrose NS. Prospective evaluation of dynamic contrast enhanced magnetic resonance imaging in the evaluation of fistula in ano. Br J Surg 1996; 83: $1396-8$.

7. Barth MM, Smith MP, Pedrosa I, Lenkinski RE, Rofsky NM. Body MR imaging at $3.0 \mathrm{~T}$ : under $\neg$ standing the opportunities and challenges. $\mathrm{Ra} \neg$ diographics 2007; 27: 1445-62; discussion 1462-4.

8. Chang KJ, Kamel IR, Macura KJ, Bluemke DA. 3.0-T MR imaging of the abdomen: comparisonwith1.5 T. Radiographics 2008; 28: 1983-8.

9. Goodsall DH, Miles WE. Diseases of the anus and rectum. London, England: Longmans, Green, 1900.

10. Eisenhammer S. A new approach to the anorectal fistulous abscess based on the high intermuscular le $\neg$ sion. Surg Gynecol Obstet 1958; 106: 595-9.

11. Chapple KS, Spencer JA, Windsor AC, Wilson D, Ward J, Ambrose NS. Prognostic value of magnetic resonance imaging in the management of fistula-in-ano. Dis Colon Rectum 2000; 43: 511-6.

12. Halligan S. Imaging fistula-in-ano. Clin Radiol 1998; 53: 85-95.

13. Buchanan G, Halligan S, Williams A, et al. Effect of MRI on clinical outcome of recurrent fistula-in-ano. Lancet 2002; 360: 1661-2.

14. Buchanan GN, Halligan S, Williams AB, et al. Magnetic resonance imaging for primary fistula in ano. Br J Surg 2003; 90: 877-81. 
15. Kuijpers HC, Schulpen T. Fistulography for fistula- in-ano: is it useful? Dis Colon Rectum 1985; 28: 103-4.

16. Guillaumin E, Jeffrey RB Jr, Shea WJ, Asling CW, Goldberg HI. Perirectal inflammatory disease: CT findings. Radiology 1986; 161: 153-7.

17. Liang C, Lu Y, Zhao B, Du Y, Wang C, Jiang W. Imaging of anal fistulas: comparison of computed tomographic fistulography and magnetic resonance imaging. Korean J Radiol 2014; 15: 712-23.

18. Law PJ, Bartram CI. Anal endosonography: tech $\neg$ nique and normal anatomy. Gastrointest Radiol 1989; 14: 349-53.

19. Buchanan GN, Halligan S, Bartram CI, Williams AB, Tarroni D, Cohen CR. Clinical examination, endosonography, and MR imaging in preopera tive assessment of fistula in ano: comparison with outcomebased reference standard. Radiology 2004; 233: 674-81.

20. Halligan S, Stoker J. Imaging of fistula in ano.Radiology 2006; 239: $18-33$. 